\title{
THE CHERNOBYL ACCIDENT, THE MALE TO FEMALE RATIO AT BIRTH AND BIRTH RATES
}

\author{
(Victor Grech. The Chernobyl Accident, the Male to Female Ratio at Birth and Birth Rates. \\ Acta Medica (Hradec Králové). 2014; 57(2): 62-7. doi: 10.14712/18059694.2014.41.)
}

To the editor: Grech's study compares the male to female ratio (sex odds) at birth before and after the Chernobyl nuclear accident in several countries exposed to Chernobyl's fallout. In Table 3 of his paper, the sex odds in two time windows, 1986-90 and 1991-95, are divided by the sex odds in 1981-85, i.e. before Chernobyl. The countries selected are Belarus, Ukraine, Russia, Finland, Sweden, Norway, and Austria. A chi-square test is used to determine whether the sex odds in the two time windows after 1985 differ from the sex odds in 1981-85. Altogether, 14 test results are presented ( 7 countries, 2 time windows). For the three countries of the former Soviet Union, significant increases are found while, for the four countries in Western Europe, all results are not statistically significant at the $5 \%$ level.

I have the following comments on the methods used.

Firstly, why does the time period for possible radiation effects include 1986? A disturbed male/female ratio arises at the time of conception but is not apparent until after birth.

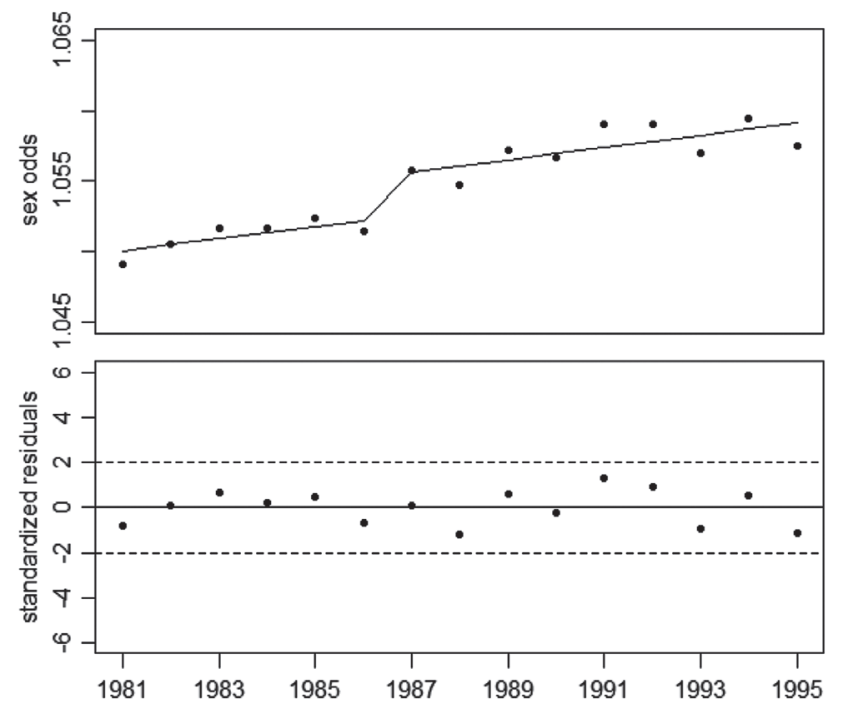

Fig. 1: Sex odds in pooled data from Belarus, Ukraine, Russia, Finland, Sweden, Norway, and Austria, and regression result (upper panel). The lower panel shows the deviations from the expected trend (standardized residuals) and the range of two standard deviations.
The Chernobyl accident occurred on April 26, 1986, so we would not expect to see any effects until 1987.

Secondly, the use of time averages does not allow us to determine a possible time trend of the sex odds. Annual data are available on the WHO website, and with these it would have been possible to apply regression analyses.

Third, instead of producing 14 individual test results, Grech could have pooled the data from the selected countries and combined the two time windows after Chernobyl to one. Then the question whether Chernobyl had an effect on the human sex ratio could be answered by a single test. This is important for two reasons: (a) it cuts down the number of results some of which could be due to chance, and (b) the larger numbers convey greater statistical strength.

A logistic regression of the annual data by myself, with a time trend and a dummy variable denoting the years 1987-95, in fact yields a statistically significant $0.3 \%$ upward shift of the sex odds in the pooled data from the seven exposed countries after Chernobyl $(\mathrm{P}=0.0093)$. This is shown in figure 1 below.

If, however, the time window chosen by Grech (1986$95)$ were used, the effect would not be significant $(\mathrm{P}=0.48)$.

\author{
Alfred Koerblein \\ Untere Soeldnersgasse 8 \\ D-90403 Nuernberg \\ Germany \\ www.alfred-koerblein.de
}

To the editor: With interest we noticed the article "The Chernobyl Accident, the Male to Female Ratio at Birth and Birth Rates" by Victor Grech in "ACTA MEDICA (Hradec Králové)" (1). The investigation by Victor Grech presents historically important findings, contributes to the issue "radiation and the sex ratio in man" $(2,3)$, and supports previous analyses of genetic consequences in the aftermath of Chernobyl in Europe (4).

Grech essentially employs a robust statistical methodology based on three 5-year intervals to investigate the sex ratio trends in eastern European and Asian countries before and after the Chernobyl nuclear power plant (NPP) accident in 1986. He reports highly significant sex ratio increases from 
1986 onward in the investigated countries after this severe nuclear catastrophe of level INES7 (http://www.iaea.org /Publications/Factsheets/English/ines.pdf).

As Grech correctly notes, trend analyses on a year by year basis are more informative and flexible compared to a temporally categorized approach. In support of Grechs overall findings, we will demonstrate this general rule by a full time series analysis for the combined sex ratio trend of Belarus, Russia, and Ukraine from 1959 to 2009; data downloaded 9/23/2014 from http://www.mortality.org.

A less well known INES5 reactor accident occurred in Chernobyl: "In September 1982, a fuel channel in the center of the core of the Unit 1 of the Chernobyl NPP was destroyed as a result of mistakes made by the personnel. A large amount of radioactive substances was released to the industrial site of the NPP and the city Pripyat. The personnel involved in the liquidation of the consequences of this accident received high irradiation doses." http://www .rri.kyoto-u.ac.jp/NSRG/reports/kr79/kr79pdf/Malko1.pdf. Therefore, we will consider in addition whether this INES5 accident at Chernobyl in 1982 also had a discernable effect on the sex ratio in Belarus, Russia, and Ukraine from 1983 onward.

Figure 1 shows the sex ratio trend of Belarus, Russia, and Ukraine combined from 1959 to 2009 . We parsimoniously model this trend by a straight line from 1959 to 1982 the year of the first major accident at Chernobyl. We then allow for a jump in 1983 (jump1) and a jump in in 1987 (jump2) and model the remaining trend from 1987 onward by a smooth 3rd degree polynomial including an interaction of time with the period from 1987 onward, similar to the approach adopted in our paper on Russian and Cuban sex ratio trend analyses (5). The significant jumps in Figure $1(\mathrm{p}<0.001)$ corroborate Grechs major findings and furthermore support the previous observation by Grech (6) that not only INES7 but also INES5 accidents, e.g. Windscale/Sellafield in 1957, may have far ranging effects on the sex ratio in affected and neighboring countries.

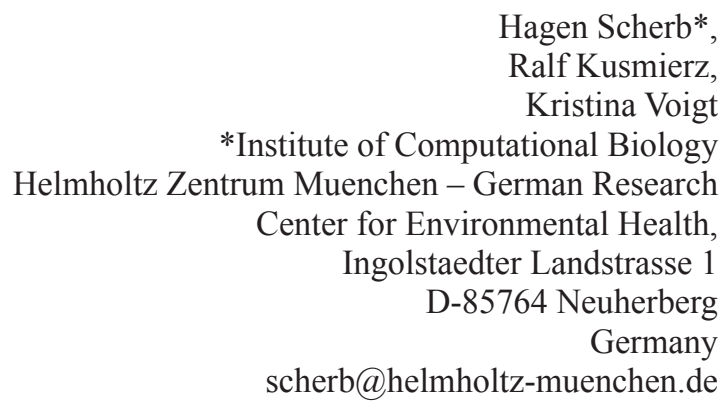

\section{References}

1. Grech V. The Chernobyl Accident, the Male to Female Ratio at Birth and Birth Rates. Acta medica 2014; 57(2): 62-7.

2. Schull WJ, Neel JV. Radiation and the sex ratio in man. Science 1958 Aug 15; 128(3320): $343-8$.

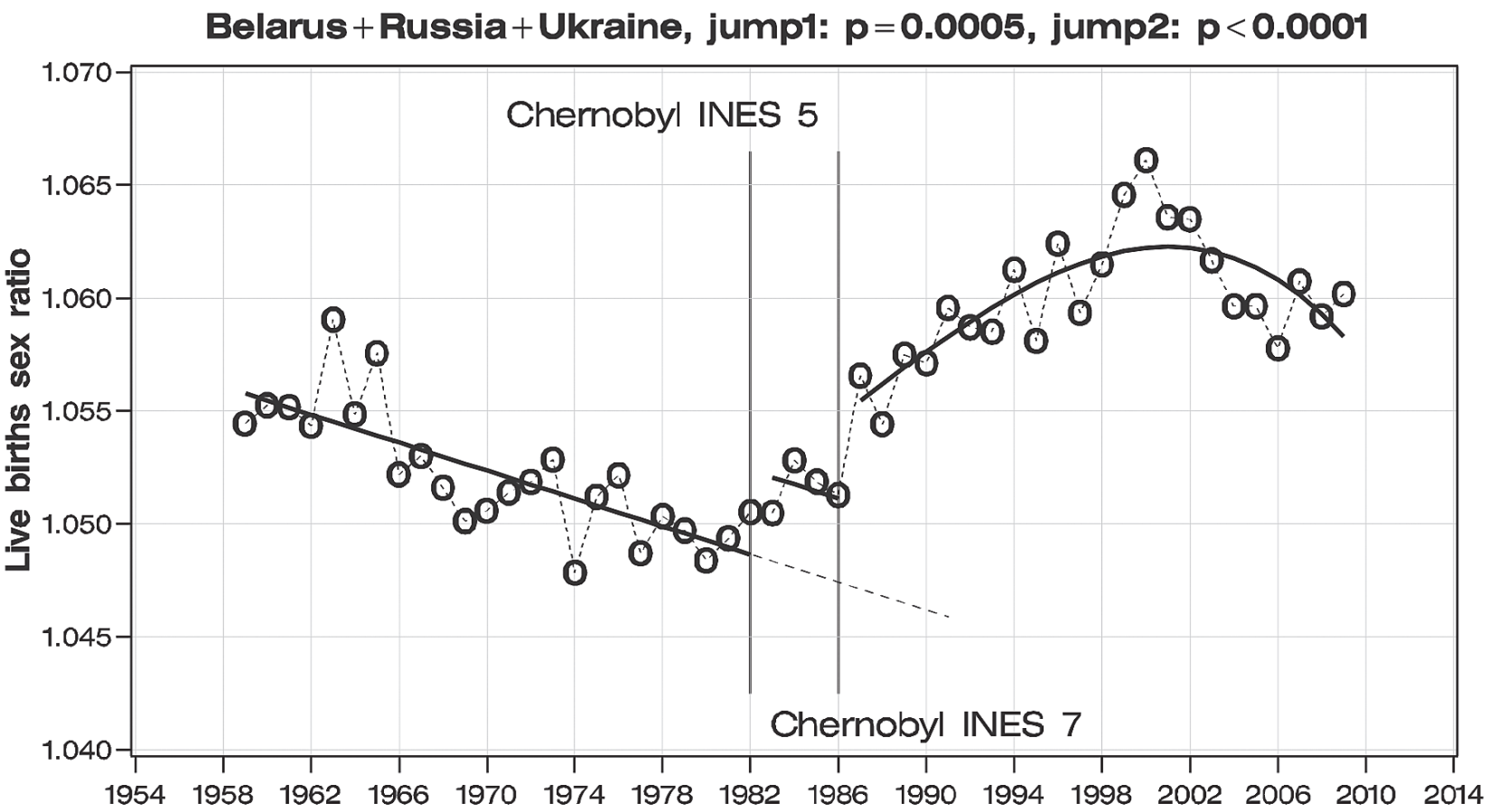

Fig. 1: Trend of the human secondary sex ratio in the combined Belarus, Russia, and Ukraine from 1959 to 2009; logistic regression model (solid line) allowing for two jumps one year after major nuclear accidents at the Chernobyl nuclear power plant (INES5 and INES7): jump1 and jump2 in 1983 and 1987, respectively. 
3. Scholte PJ, Sobels FH. Sex Ratio Shifts among Progeny from Patients Having Received Therapeutic X-Radiation. American journal of human genetics 1964 Mar; 16: 26-37.

4. Scherb H, Voigt K. The human sex odds at birth after the atmospheric atomic bomb tests, after Chernobyl, and in the vicinity of nuclear facilities. Environmental science and pollution research international 2011 Jun; 18(5): 697-707.

5. Scherb H, Kusmierz R, Voigt K. Increased sex ratio in Russia and Cuba after Chernobyl: a radiological hypothesis. Environmental health: a global access science source $2013 ; 12: 63$

6. Grech V. Births and male:female birth ratio in Scandinavia and the United Kingdom after the Windscale fire of October 1957. The International journal of risk \& safety in medicine $2014 ; 26(1): 45-53$.

The authors reply: Koerblein correctly notes that the time periods chosen for analysis include 1986 and comments that conception effects for events occurring around 26th April 1986 would be manifest in January. However, this would have ignored potential sex ratio skew in mothers who were already pregnant. Hence, 1986 was also included.

He also observes that the use of averages and the amalgamation of data have disadvantages but then goes on to comment that pooling the dataset would have increased the power of the study. As always, there are often several ways (all correct) to analyse data, with varying pros and cons. Researchers should, in principle, use methodologies which are the simplest possible for the task at hand, tests with which they are familiar and which are least likely to result in type 1 or type 2 errors.

The advantages of chi tests are that they are simple to apply, robust and familiar to almost all readers in terms of application. These tests have been widely used by this author and appear to be universally accepted in the analysis of male to female ratios, not only in relation to radiation effects $(1,2)$, but also for the large scale analysis of continental and regional datasets $(3-5)$, for country analysis $(6,7)$, and even for micro data such as Maltese elections (8).

\section{Victor Grech \\ Department of Paediatrics Mater Dei Hospital Malta victor.e.grech@gov.mt}

\section{References}

1. Grech V. The Chernobyl Accident, the Male to Female Ratio at Birth and Birth Rates. Acta medica 2014: 57(2): 62-7.

2. Grech V. Births and male:female birth ratio in Scandinavia and the United Kingdom after the Windscale fire of October 1957. The International journal of risk \& safety in medicine 2014; 26(1): 45-53.

3. Grech V, Savona-Ventura C, Vassallo-Agius P. Unexplained differences in the sex ratio at birth in Europe and North America. Br Med J 2002; 324: 1010-1011.

4. Grech V. Secular trends in sex ratios at birth in South America over the second half of the 20th century. J Pediatr (Rio J) 2013; 89: 505-9.

5. Grech V. Secular trends in newborn sex ratios. Early Hum Dev 2014. pii: S03783782(14)00204-7.

6. Grech V. Secular trends and latitude gradients in the male-female ratio at birth in Yugoslavia and the ex-Yugoslavian States. Acta Medica 2013; 56: 47-51.

7. Grech V. The Japanese decline in secondary sex ratio correlates with percentage change in GDP/annum. Int J Tropical Dis Health 2015; 5: 130-135.

8. Grech V. The male:female ratio at birth is depressed by Maltese parliamentary elections and increased by other non-electoral events. Int J Tropical Dis Health 2014; 4: 1123-1131. 